\title{
Quinolizidine Alkaloids: Biochemistry, Metabolism, and Function in Plants and Cell Suspension Cultures
}

\author{
Michael Wink ${ }^{1}$ \\ Received: January 27,1987
}

\begin{abstract}
Quinolizidine alkaloids constitute about $2 \%$ of the alkaloids that are known from plants. In this report, data on chromatography (TLC, cGLC), spectroscopy (MS, NMR), occurrence, biosynthesis (tracer studies, enzymatic experiments), accumulation, transport, degradation, biological activities (pharmacology, chemical ecology), and alkaloid formation in cell cultures are reviewed.
\end{abstract}

Quinolizidine alkaloids (QA) have been studied in a number of laboratories during the last 100 years. Although of minor pharmaceutical importance (sparteine is used as an antiarrhythmic compound), interest in this group of alkaloids has increased within the last 15 years, which can be seen in the growing number of articles and reviews in this field $(7,8,24,58,91-93)$. It is not my intention in this review to cover the literature exhaustively, but rather to present an overview of the most significant and interesting aspects of QA biosynthesis and QA metabolism in plants and cell suspension cultures.

\section{Chemistry of Quinolizidine Alkaloids}

\subsection{Structural Types}

Quinolizidine alkaloids represent about $2 \%$ of the 7000 known alkaloids from plants. QA can be divided in more than 6 structural groups (Fig. 1): A. Lupinine (1) and its esters $(1,7)$. B The tetracyclic QA, such as sparteine (2) and lupanine (3) which can be modified by additional keto groups and up to two hydroxyl groups (7). The hydroxylated lupanines form esters with aliphatic and aromatic acids $(2,7) . \mathrm{C}$. The $\alpha$-pyridones [e.g. anagyrine (4)], D. The tricyclic QA with an allylic side chain instead of ring D, such as tetrahydrorhombifoline (5) (7). E. Matrine alkaloids which can be modified in a similar way as type B and C. F. The alkaloids of the multiflorine-type with a modified A-ring. G. Other types (7). For a compilation of the known QA see (7, but also 3-8).

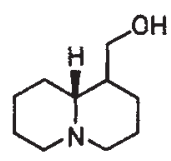

1 lupinine

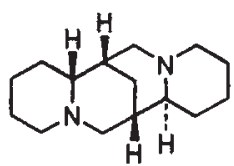

2 sparteine

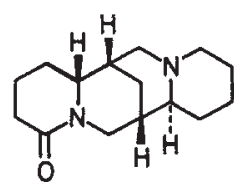

3 lupanine

\footnotetext{
${ }^{1}$ Genzentrum der Universität München, Pharmazeutische Biologie, Karlstr. 29, D-8000 München 2, Federal Republic of Germany.
}

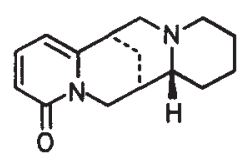

4 anagyrine<smiles>O=C1CCC[C@H]2C3CCCN4CCC[C@@H](CN12)C34</smiles>

7 matrine<smiles>C=CCCN1CC2CC(C1)[C@H]1CCCC(=O)N1C2</smiles>

5 tetrahydrorhombifoline<smiles>O=c1cccc2n1CC1CNCC2C1</smiles>

6 cytisine
Fig. 1. Structural types of quinolizidine alkaloids [for review, see (7)].

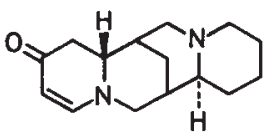

8 multiflorine tion of the Kovats-retention indexes or of retention times of about 50 QA is given in $(7,14,17-19)$. HPLC is a convenient method for the preparative isolation of QA [RP 18, solvents: $20 \% \mathrm{MeOH}, 20 \%$ isopropanol in $\mathrm{H}_{2} \mathrm{O} 0.01 \mathrm{M}$ phosphate buffer, pH 6.4; (21)].

For the identification of QA IR-spectroscopy, which had been used as the main method a few decades ago, has been widely substituted by NMR and mass spectrometry. NMR data $\left({ }^{1} \mathrm{H},{ }^{13} \mathrm{C}\right)$ have been reported in $(20)$ and reviewed in $(7,8)$. Often mass spectrometry has been the method of choice in phytochemical studies of QA $(7,9,13-19)$, especially in combination with GLC (GLC-MS), when the identification of known structures is demanded. For many QA EI-MS gives instructive fragmentation patterns [for mass spectral data see (719)]. CI-MS is very useful for alkaloids of type D and for esters, which do not give rise to prominent molecular ions in the EI- 
mode (data in 19). For this purpose also field-desorption (FD) and fast atom bombardment (FAB-MS) mass spectrometry have been employed $(17,21)$. In laser desorption MS intensive $\left[\mathrm{M}+\mathrm{H}^{+}\right]$ions are generated (22); with the LAMMA 1000-instrument this method can provide data on the spatial distribution of QA in plant tissues (22).

\subsection{Organic Synthesis}

Work on partial and total synthesis of QA has been reviewed in $(8,92)$.

\section{Biology and Biochemistry of Quinolizidine Alkaloids}

\subsection{Occurrence}

QA are characteristic secondary metabolites of the Fabaceae, especially of the tribes Sophoreae, Podalyrieae s. 1, , and Genisteae $(3,6,7,23,24)$. In addition, isolated occurrences of QA have been reported from Anabasis aphylla (Chenopodiaceae), Caulophyllum thalictroides, Leontice spec. (Berberidaceae), Chelidonium majus (Papaveraceae), Castilleja miniata, Orobanche rapum-genistae (Scrophulariaceae), Osyris alba (Santalaceae), Solanum lycocarpum (Solanaceae), and in the Ranunculaceae $(21,24,25)$. Cell cultures of Conium maculatum, Daucus carota (Umbelliferae), Chenopodium rubrum, Spinacia oleracea (Chenopodiaceae), and Symphytum officinale (Scrophulariaceae) produced lupanine in minute amounts especially after stimulation with chemically defined "elicitors" (26). From these data on the occurrence of QA in plants and cell cultures it was concluded that the genes which code for lupanine biosynthesis are not restricted to the Fabaceae but are widely distributed in the plant kingdom. Considering the distribution of nicotine, ergot alkaloids, and morphine similar conclusions have been drawn (26-28).

\subsection{Biosynthesis}

\subsubsection{Tracer Studies}

In the 1960 's it was established by Schütte, Mothes and coworkers that lysine and its decarboxylation product cadaverine serve as the only precursors for the bi- and tetracyclic QA (for review, see Schütte 24). Spenser and Robins and their respective coworkers have studied this question again during the last 12 years using deuterium-, carbon 13- and nitrogen 15-labelled cadaverines and analyzed the products by NMR $(29-35,39,94$, $95,99,100)$. Using this powerful method these authors could confirm the results obtained by Schütte et al. (24). They could not, however, identify any intermediates between cadaverine, 5-aminopentanal, or $\Delta^{1}$-piperideine (the deamination product) and the bi- or tetracyclic alkaloids (Fig. 2). These authors showed that the bonds between $\mathrm{C}-2$ and $\mathrm{N}-1$ and between $\mathrm{C}-15$

1

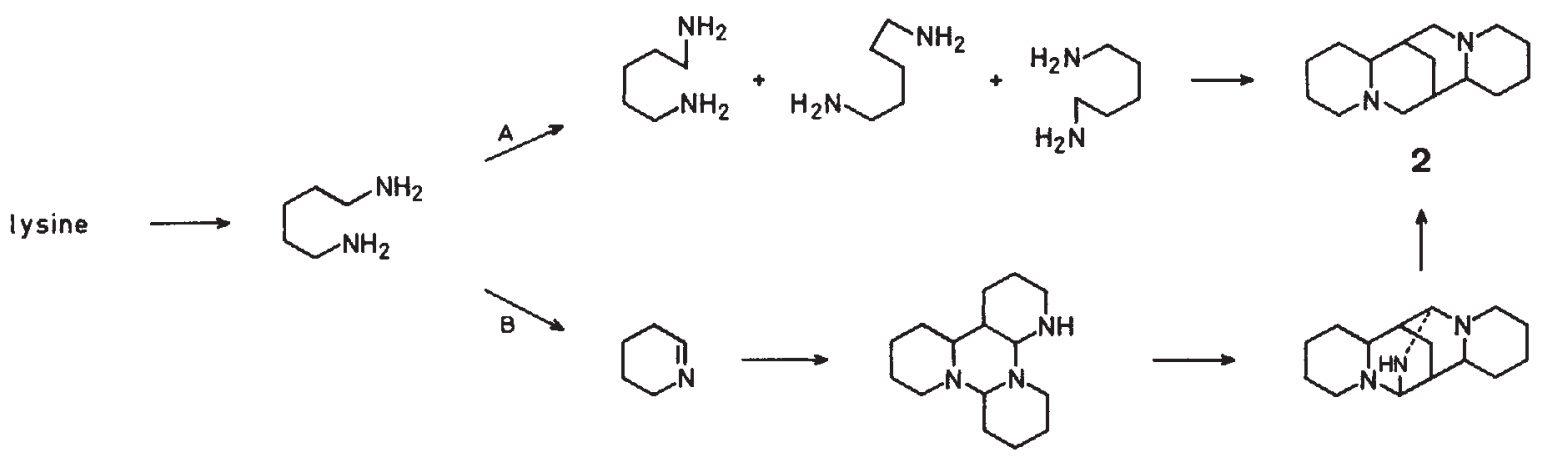

II

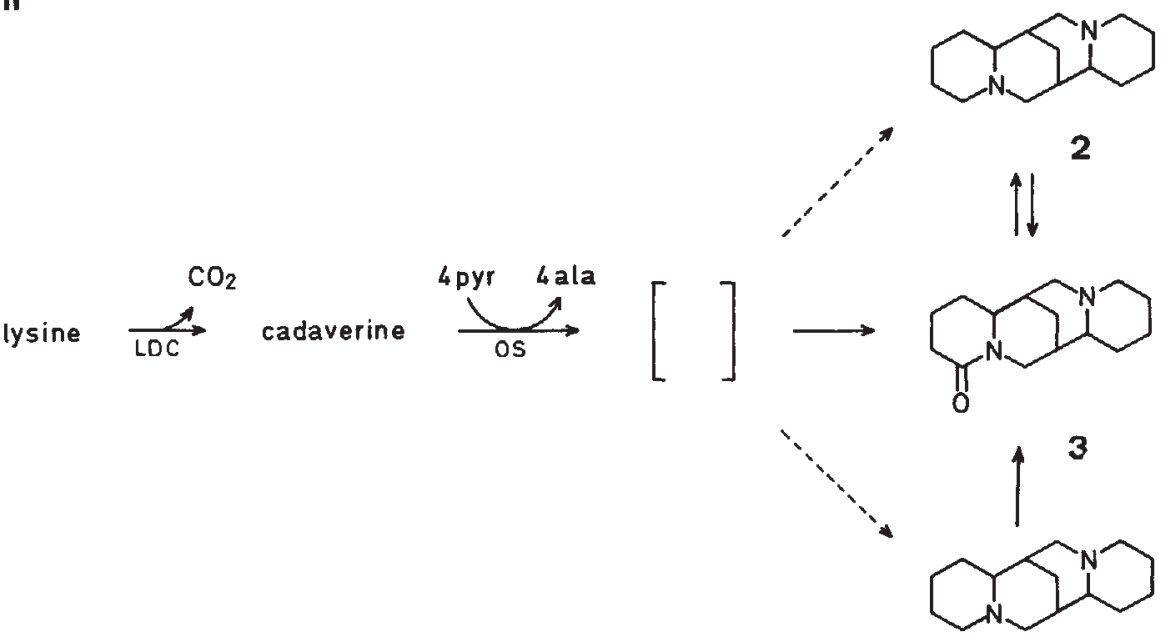

Fig. 2. Schemes of quinolizidine alkaloid biosynthesis I. Models derived from tracer studies:
A. "Mothes-Schütte"-model
B. "Golebiewski-Spenser"-model

II. Enzymatic evidence of QA-biosynthesis $\mathrm{LDC}=$ lysine decarboxylase, $\mathrm{OS}=$ oxosparteine synthase 
and $\mathrm{N}-16$ were stable and that the hydrogen atoms at the 10 and 17-positions were retained, i.e. that keto groups are not formed at these positions during biosynthesis. Also a removal and replacement of hydrogen at C-8 can be excluded (96).

Two hypothetical models for the biosynthesis of the tetracyclic alkaloids and have been formulated which are in accordance with the labelling patterns observed. (Fig. 2): 1. The "traditional" one, which is based on Mothes and Schütte (27). 2. The Golebiewski and Spenser model $(29,99)$ which assumes the trimerization of $\Delta^{1}$-piperideine into isotripiperideine. Isotripiperideine is then isomerized to sparteine. A similar model has been postulated for the biosynthesis of the matrine type alkaloids (32). The critical experiment to prove this hypothesis, i.e. to show that isotripiperideine is incorporated into QA has not been reported.

There is no agreement whether sparteine or lupanine is the first labelled tetracyclic alkaloid. Since sparteine is, chemically, the more "primitive" alkaloid, many authors assume that it is also the first alkaloid and that lupanine and the other alkaloids derive from it. However, it is lupanine which is most widely distributed in the plant kingdom and there is a number of species which do not contain sparteine $(7,14,21)$. Short term experiments with labelled $\mathrm{CO}_{2}(36,37)$ or $\left[{ }^{14} \mathrm{C}\right]$-cadaverine $(52)$ showed that the radioactive label could only be recovered in lupanine in species which do not accumulate sparteine. In species where sparteine was the major QA (i.e. L. arboreus), it became labelled first $(36,52)$. The most likely explanation is that an intermediate common to both sparteine and lupanine exists, which could be a dehydrosparteine $(36,38)$.

For lupinine biosynthesis see $(30,31,34,94,95,99)$.

For the biosynthesis of the cytisine-type alkaloids it has been postulated that lupanine is converted into 5,6-dehydrolupanine which is further oxidized to anagyrine, rhombifoline, cytisine and $N$-methylcytisine (37). A 6-hydroxylupanine has been isolated recently which is thought to be the direct precursor for 5,6-dehydrolupanine (38). For the formation of cytisine in Baptisia it was postulated that ring $A$ must be cleaved and ring $D$ converted into a pyridone (39).

\subsubsection{Enzymatic Studies on $Q A$ Biosynthesis}

A lysine decarboxylase, which converts lysine into cadaverine was discovered in lupin cell cultures and intact plants and could be localized subcellularly in the chloroplast $(40,41)$. From cell suspension cultures a cell-free extract was obtained in which cadaverine was deaminated by a transaminase with pyruvate as the amino acceptor (42). The resulting 5-aminopentanal was directly incorporated into tetracyclic alkaloids, of which 17-oxosparteine was identified by GLC-MS as the main and sparteine as a minor product $(42,43)$. In intact chloroplasts cadaverine was incorporated into lupanine instead (44). Because 17-oxosparteine was the major product in the assays, a model was formulated with enzyme-bound intermediates and 17-oxosparteine as the key intermediate (43) and the enzyme was named "oxosparteine synthase". 17-Oxosparteine was found to be converted by cell cultures and crude enzyme preparations into lupanine (45).

Recent tracer experiments did not confirm the intermediacy of 17-oxosparteine, at least for intact plants $(35,94-96,99$, 100). Two possible explanations can be forwarded for the obvious discrepancy: 1. The enzyme system in suspension-cultured cells might differ from that of intact plants. 2 . The enzyme assays were performed in cell-free extracts (since the enzyme was difficult to purify) which contained a number of other enzyme activities. It might thus be possible that an intermediate such as the postulated dehydrosparteine (see 2.2.1.) or sparteine were oxidized to 17-oxosparteine by a second enzyme (QA of the sparteine-type are easily oxidized at the 17-position). Therefore, the question of the product of the "oxosparteine synthase" reaction and the reaction mechanism (43) have to be reconsidered (which is currently being done in my group). Most OS-assays were performed using $\left[{ }^{14} \mathrm{C}\right]$-cadaverine as a substrate. After thin layer chromatography of the products in ethanol/ammonia (8.5/3) the zones of sparteine and 17-oxosparteine were eluted and evaluated by liquid scintillation counting. These enzyme activities always matched the biosynthetic activity of a given tissue (46) and were correlated with lysine decarboxylase activity (41). We are certain therefore, that these enzyme assays actually determined the activity of the alkaloid synthase reaction and that the conclusions drawn from further experiments $(26,44,46,47)$ are still valid.

A number of additional enzymatic steps have been reported, such as the formation of 13-tigloyl-oxylupanine by a tigloylCoA: 13-hydroxylupanine $O$-tigloyltransferase (48) and the synthesis of $N$-methylcytisine by an SAM: cytisine $N$-methyltransferase (49). For a review of further enzymatic steps and the properties of the enzymes involved see Wink and Hartmann (50).

\subsection{Biology and Physiology of $Q A$}

\subsubsection{Site of QA Biosynthesis}

QA formation was observed in the aerial parts of legumes only (24), although the whole plant accumulates these alkaloids (for review of the older literature see Schütte $24 ; 51$ ). This finding could be confirmed in our laboratory: Feeding $\left[{ }^{14} \mathrm{C}\right]$-cadaverine to roots, stems or leaves of lupins, which derived either from mature plants or from organ cultures, incorporation of the precursor into lupanine and other QA could only be observed in green stems or leaves (52). Furthermore, "oxosparteine synthase" could be recorded in green tissues only (51).

In lupin leaves, the enzymes of lysine and lupanine formation could be localized in the stroma of chloroplasts $(44,47)$, where also the biosynthesis of lysine takes place. QA biosynthesis is regulated by light $(18,50,70)$ and fluctuates diurnally $(18,70)$.

\subsubsection{Sites of $Q A$ Accumulation}

2.3.2.1. Developmental and Seasonal Fluctuation in Plants QA are present in all parts of a plant and have been recorded even in the pollen or petals of lupins $(51,53)$. The highest alkaloid concentrations are usually reached in the mature seeds, which can contain up to $5 \%$ alkaloid per dry weight (equivalent to $200 \mathrm{mmol} / \mathrm{kg}$ ). Legumes with many small seeds have a lower, species with few and big seeds generally the highest alkaloid content (25), an observation which might be relevant in an ecological context (s. 2.4.2.; 25). Mutants have been isolated from Lupinus albus, L. luteus, and L. angustifolius (the so-called "sweet lupins"), which produce only small amounts of QA (as low as $10 \mathrm{mg} / \mathrm{kg} \mathrm{DW}$ ). These varieties are increasingly employed in agriculture, since lupin seeds contain up to $40 \%$ valuable protein and up to $20 \%$ lipids and are thus comparable to soy beans (54-56).

Alkaloid levels in stems and leaves of lupins and broom usually fall in the range between $0.1-20 \mathrm{~g} / \mathrm{kg} \mathrm{FW}$. They depend on the developmental stage of the plants and on the season. The fluctuation of alkaloid content and alkaloid patterns during germination and seedling development of 10 species has been 
described by Wink and Witte (57). Alkaloids are translocated from the cotyledons to the growing roots and epicotyls during the early stages of germination. When the seedlings develop leaves the de novo synthesis of QA sets in and only ceases at the end of the vegetation period, especially when the seeds of a lupin have reached maturity $(58,59)$. QA are not present in senescing leaves or shoots to any substantial degree (51); they must have been metabolized or delocalized before. In perennial species QA are also concentrated in the roots (i.e. $L$. polyphyllus) or the stem bark (in woody species, such as Laburnum or Petteria) $(51,60)$.

\subsubsection{Tissue-Specific Accumulation of $Q A$}

Using histochemical methods the distribution of QA within plants has been studied (for review see Molisch 61, Thunmann 62). Marked concentrations of QA were observed in epidermal and subepidermal tissues of stems and leaves. This finding could be confirmed using modern analytical techniques such as laser desorption MS (LAMMA 1000) (22) or capillary GLC (63). The alkaloid concentrations in these peripheral cell layers range between 20 and $200 \mathrm{mmol} / \mathrm{kg} \mathrm{FW}$.

\subsubsection{Transport of QA}

QA are accumulated also in tissues which do not synthesize them. Therefore, a transport of QA had to be assumed. Indirect biological evidence indicated that $\mathrm{QA}$ must be present in the phloem sap of legumes: 1 . QA could be detected in Orobanche rapum-genistae, known to tap the phloem of Cytisus host plants (64). 2. QA were found in aphids and in their honey dew, which also exploit the phloem of a plant $(60$, 65,66 ). In $L$. angustifolius and $L$. consentinii it was shown by direct GLC analysis that QA are predominantly present in the phloem but not in the xylem sap (65). In phloem sap collected from fruit tips of $L$. albus lupanine (3) was present in a concentration of about $3.4 \mathrm{mM}$ and fluctuated in a light-mediated diurnal rhythm (18). It is thus certain that QA are transported in the phloem sap, which would explain how the alkaloids that are formed in the leaves are distributed all over a lupin plant.

\subsubsection{Intracellular Storage and Transport of QA}

Like other secondary metabolites (67) QA are also stored in vacuoles (68). Transport of lupanine (3) into isolated vacuoles is catalyzed by a specific carrier protein and energetized by an $\mathrm{H}^{+}$-ATPase and $\mathrm{a} \mathrm{K}^{+}$-dependent membrane potential $(68,78)$.

\subsubsection{Degradation of QA}

Like many other secondary metabolites (69) QA are not the end products of metabolism but show a high degree of turnover. Turnover of QA is indicated by a number of observations: 1. The level of QA in leaves and other organs of lupins follows a diurnal cycle with high values during the day and low ones during the night $(18,70)$. 2. Total amounts of $\mathrm{QA}$ are reduced by up to $80 \%$ during germination and seedling development (57). 3. QA that are added to cell suspension cultures disappear within a week of cultivation $(46,70,85)$. Since nitrogen is a limiting factor for plants, we have postulated that the nitrogen which is set free from degraded QA can be reused in the metabolism of a plant. This assumption was indirectly confirmed: Cell cultures, grown on media with the QA sparteine as the sole nitrogen source grew slowly and survived for more than 6 months, whereas control cultures on nitrogen-free agar had died within 6 weeks (57).

\subsection{Biological Activities of $Q A$}

\subsubsection{Biochemical and Pharmacological Properties}

QA have a wide variety of biological activities (for review, see 7). They are toxic or inhibitory for most organisms. Relatively well-studied are the activities of sparteine and lupinine in vertebrates, especially rat and man: isolated QA can be antiarrhythmic and oxytocic (sparteine, lupanine; 7), hypoglycemic (lupinine), cytotoxic and antipyretic (matrine, 72), hallucinogenic (cytisine, $N$-methylcytisine $(7,73,77)$ ), teratogenic (anagyrine, 74). Sparteine is used therapeutically as an antiarrhythmic drug and in obstetrics, whereas lupinine and matrine have been in use in folk medicine in Eastern Asia (72). Most of the over 150 QA have not been tested at all in any of the abovementioned areas and the mechanism of their action in living systems has to be elucidated in most instances.

\subsubsection{Function as Chemical Defence Compounds in Plants}

Isolated QA were shown to inhibit the multiplication of potato $X$-virus (53), of various bacteria $(75)$, and fungi $(75,76)$. They repell the feeding of snails and slugs $(77,78)$ and vertebrates (58) and are toxic for insects (59). $\mathrm{ED}_{50}$ values were in the range of $0.5-5 \mathrm{mM}$, i.e. rather high as compared to strong toxins. These concentrations are lower, however than the QA concentrations found in the intact plant, especially when the QA concentrations of epidermal tissues or those of seeds are taken into consideration $(25,53)$. Since plants must have mechanisms for their protection against pathogens and herbivorous animals, QA might be a suitable means for defence, since most legumes have soft tissues which are not defended by thorns or stinging hairs. Legume species which contain QA usually do not accumulate other secondary metabolites to a similar degree. QA-free legumes on the other hand accumulate toxic non-protein amino acids, pyrrolizidine alkaloids, cyanogenic glycosides, proteinase inhibitors, or lectins instead $(6,25)$, for which a defensive role is also assumed $(80-83,97)$.

Especially those organs or tissues which are important for survival and reproduction (e.g. flowers, fruits, seeds, seedlings) store QA at concentrations which exceed the inhibitory concentrations found in vitro. Storage in epidermal tissues might have evolved, because this peripheral tissue has to ward off attacks in the first instance. The level of QA increased by a factor 2-4 within 2-4 hours after experimentally wounding the leaves of L. polyphyllus (79). If a similar response takes place in the intact plant upon wounding by predators or pathogens, the effect of the already existing alkaloids would be further increased and amplified.

It could be shown experimentally that QA are obviously relevant as chemical defence compounds for lupins, since alkaloid-free lupin varieties, when grown together with their alkaloid-rich wild types were selectively eaten or parasitized by herbivores (e.g. rabbits, leaf miners, and aphids) $(25,53)$. Thus QA provide one of the few examples where the importance of a secondary metabolite for the fitness of a plant has been clearly demonstrated (for review, see 80-84).

\subsubsection{Function as Defence Compounds in Insects}

No chemical defence is absolute and nearly all plants which are otherwise protected against herbivores by their toxins, have a few pathogens or herbivores which have overcome the defence systems. A few aphids have been described which are specialized on alkaloid-rich lupins or broom plants. These 
aphids obviously accumulate QA, which they obtain from the phloem sap and QA concentrations between 1 and $20 \mathrm{mM}$ have been reported $(60,65,66)$. For Macrosiphon albifrons it could be shown that carnivorous beetles (Carabids) will be narcotized for over $48 \mathrm{~h}$ when they feed on these aphids (66). Thus an advantage of specialization might be the acquisition of chemical defence compounds in addition to that of protein, carbohydrates and lipids from plants. A similar example are Danaid butterflies which obtain cardenolides and pyrrolizidine alkaloids from their food plants (for review 84,98 ).

\subsection{Quinolizidine Alkaloids in Cell Cultures}

Callus and suspension cultures of Lupinus polyphyllus, $L$. luteus, L. albus, L. hartwegii, L. mutabilis, Cytisus scoparius, C. purpureus, Genista tinctoria, Baptisia australis, Sophora japonica, and Laburnum alpinum produce only limited amounts of QA, which are 2 to 3 orders of magnitude lower than the alkaloid concentrations found in intact plants $(2,13$, $14,16,17,21$, and Wink unpublished). Lupanine was the main alkaloid in all cell cultures, irrespective of the alkaloid patterns prevailing in the intact plant $(14,21)$.

Alkaloid formation was substantially higher in green, chloroplast-containing cultures $(64,85)$ grown in the light (compare 2.3.1.) which is in agreement with the site of QA biosynthesis in chloroplasts.

Storage capacity of the cell cultures (78) for QA seems to be low and QA are rapidly degraded by endo- and exoenzymes $(46,71,86,87)$. For a possible explanation of the failure of cell cultures to produce significant amounts of QA see (88-90).

\section{Acknowledgements}

The work of the author, reviewed in this article, was supported by grants and a Heisenberg-fellowship of the Deutsche Forschungsgemeinschaft. I thank Prof. Dr. T. Hartmann (Braunschweig) and Prof. Dr. M. H. Zenk (München) for generous support and encouragement, $\mathrm{C}$. Theuring and S. Schmidt for technical assistance.

\section{References}

(1) Murakoshi, I., Ogawa, M., Toriizuka, K., Haginiwa, J., Ohmiya, S., Otumaso, H. (1977) Chem. Pharm. Bull. 25, 527.

(2) Wink, M. , Hartmann, T. (1982) Planta Med. 156, 560.

(3) Mears, J. A., Mabry, T. J. (1971) in: Chemotaxonomy of the Leguminosae, (Harborne, J. B., Boulter, D., Turner, B. C., eds.), p. 73, Academic press, London, New York.

(4) Sadykov, A. S., Aslanow, C. A., Kushmuradow, J. G. (1975) Alkaloidi chinolisidinova rjada. Nauka, Moskow.

(5) Faugeras, G., Paris, R. (1971) Boissiera 19, 201.

(6) Polhill, R. M., Raven, P. H. (1981) Advances in legume systematics. Royal Bot. Gardens, Kew, U.K.

(7) Kinghorn, A. D., Balandrin, M. F. (1984) In Alkaloids: Chemical and biological perspectives, (Pelletier, W. S., ed.), p. 105, Wiley, New York.

(8) Saxton, J. E., Grundon, M. F. (1971-1983) The Alkaloids (London), vol. 1-13.

(9) Cho, Y. D., Martin, R. O. (1971) Anal. Biochem. 44, 49.

(10) Kinghorn, A. D., Salim, M. A., Smolenski, S. S. (1980) Phytochemistry 19, 1705.

(11) Kinghorn, A. D., Balandrin, M. E., Lin, L. J. (1982) Phytochemistry 21, 2269.

(12) Murakoshi, I., Kidoguchi, E., Nakamura, M., Haginiwa, J,, Ohmiya, S., Higashiyama, Otomasu, H. (1981) Phytochemistry 20,1725 .
(13) Wink, M., Witte, L., Schiebel, H. M., Hartmann, T. (1980) Planta Med. 38, 238.

(14) Wink, M., Witte, L., Hartmann, T., Theuring, C., Volz, V. (1983) Planta Med. 48, 253.

(15) Hatzold, Elmadfa, I., Gross, R., Wink, M., Hartmann, T., Witte, L. (1983) J. Agric. Food. Chem. 31, 934.

(16) Wink, M., Hartmann, T., Witte, L., Schiebel, H. M. (1981) J. Nat. Prod. 44, 14

(17) Wink, M., Schiebel, H. M., Witte, L., Hartmann, T. (1982) Planta Med. 44, 15.

(18) Wink, M., Witte, L. (1984) Planta Med. 161, 519.

(19) Wink, M., Witte, L. (1985) Z. Naturforsch. 40c, 767.

(20) Bohlmann, F., Zeisberg, R. (1975) Chem. Ber. 108, 1043.

(21) Wink, M. (1984) Stoffwechsel und Funktion von Chinolizidinalkaloiden in Pflanzen und pflanzlichen Zellkulturen, Habilitationthesis, Technische Universität Braunschweig.

(22) Wink, M., Heinen, H. J., Vogt, H., Schiebel, H. M. (1984) Plant. Cell. Rep. 3, 230.

(23) Nowacki, E., Waller, G. R. (1977) Rev. Latinoameric, Quim. 8, 49.

(24) Schütte, H. R. (1969) in: Biosynthese der Alkaloide (Mothes, K., Schütte, H. R., eds.) p. 324, VEB, Berlin.

(25) Wink, M. (1985) P1. Syst. Evol. 150, 65.

(26) Wink, M., Witte, L. (1983) FEBS lett. 159, 196.

(27) Hegnauer, R. (1958) Chemotaxonomische Betrachtungen. V. Die systematische Bedeutung des Alkaloidmerkmals. Planta Med. 6, 8.

(28) Mothes, K., Schütte, H. R. (1969) Die Biosynthese der Alkaloide, VEB Berlin.

(29) Golebiewski, W. M., Spenser, I. D. (1976) J. Am. Chem. Soc. 98, 6726.

(30) Golebiewski, W. M., Spenser, I. D. (1983) J. Chem. Soc. Chem. Comm. 1509.

(31) Golebiewski, W. M., Spenser, I. D. (1984) J. Am. Chem. Soc. $106,1441$.

(32) Leeper, F. J., Grue-Sørensen, G., Spenser, I. D. (1981) Can. J. Chem. 59, 106.

(33) Rana, J., Robins, D. J. (1983) J. Chem. Soc. Chem. Commun. 1335.

(34) Rana, J., Robins, D. J. (1984) J. Chem. Soc. Chem. Commun. 81.

(35) Fraser, A. M., Robins, D. J. (1984) J. Chem. Soc., Chem. Commun. 1477.

(36) Cho, Y. D., Martin, R. O., Anderson, J. N. (1971) J. Am. Chem. Soc. 93, 2087.

(37) Cho, Y. D., Martin, R. O. (1971) Can. J. Biochem. 49, 971.

(38) Asres, K., Phillipson, D. J., Mascagni, P. (1986) Phytochemistry $25,1449$.

(39) Fraser, A. M., Robins, D. J. (1986) J. Chem. Soc., Chem. Commun. 545.

(40) Hartmann, T., Schoofs, G., Wink, M. (1980) FEBS lett. 115, 35.

(41) Schoofs, G., Teichmann, S., Hartmann, T., Wink, M. (1983) Phytochemistry 22, 65.

(42) Wink, M., Hartmann, T. (1979) FEBS lett. 101, 343.

(43) Wink, M., Hartmann, T., Schiebel, H. M. (1979) Z. Naturforsch. $34 c, 704$.

(44) Wink, M., Hartmann, T., Witte, L. (1980) Z. Naturforsch. 35c, 93.

(45) Wink, M., Hartmann, T., Witte, L. (1980) Planta Med. 40, 31.

(46) Wink, M., Hartmann, T. (1982) in: Plant tissue culture 1982 (Fujiwara, A., ed.), p. 333, IAPTC, Tokyo.

(47) Wink, M., Hartmann, T. (1982) Plant Physiol. 70, 74.

(48) Wink, M., Hartmann, T. (1982) Planta Med. 156, 560.

(49) Wink, M. (1984) Planta Med. 161, 339.

(50) Wink, M., Hartmann, T. (1985) in: Natural products chemistry (Zalewski, R. I., Skolik, J. J., eds.), p. 511, Elsevier, Amsterdam.

(51) Wink, M., Hartmann, T. (1981) Z. Pflanzenphysiol. 102, 337.

(52) Wink, M. (1987) (submitted).

(53) Wink, M. (1987) in: Allelochemicals, role in agriculture, forestry and ecology (Waller, G. R. ed.), p. 524 ACS-Symp. Series 330. 
(54) Gross, R., Bunting, E. S. (1982) Agricultural and nutritional aspects of lupines. GTZ, Eschborn.

(55) Bellido, L. L. (1983) Proceedings 2. International lupin conference. ILA, Madrid.

(56) Proceedings 3. International lupine conference, ILA, La Rochelle.

(57) Wink, M., Witte, L. (1985) Z. Naturforsch. 40c, 767.

(58) Waller, G. R., Nowacki, E. (1978) Alkaloid biology and metabolism in plants, Plenum Press, New York, London.

(59) Wink, M. (1984) in: Proc. 3. Int. lupin Conf., p. 325, ILA, La Rochelle.

(60) Wink, M., Witte, L. (1985) Phytochemistry 24, 2568.

(61) Molisch, H. (1923) Mikrochemie der Pflanze, G. Fischer, Jena.

(62) Thunmann, O., Rosenthaler, L. (1931) Pflanzenmikrochemie, Bornträger, Berlin.

(63) Wink, M. (1986) Z. Naturforsch. 41c, 375.

(64) Wink, M., Witte, L., Hartmann, T. (1981) Planta Med. 43, 342.

(65) Wink, M., Hartmann, T., Witte, L., Rheinheimer, J. (1982) Z. Naturforsch. 37c, 1081.

(66) Wink, M., Römer, P. (1986) Naturwissenschaften 73, 210.

(67) Matile, P. (1984) Naturwissenschaften 71, 18.

(68) Mende, P., Wink, M. (1987) J. Plant. Pyhsiol. (in press).

(69) Barz, W., Köster, J. (1981) In Biochemistry of plants, vol. 7., p. 35, Academic press, New York.

(70) Wink, M., Hartmann, T. (1982) Z. Naturforsch. 37c, 369.

(71) Wink, M. (1985) in: Primary and secondary metabolism of plant cell cultures (Neumann, K. H., Barz, W., Reinhard, E., eds.), p. 107, Springer, Berlin, Heidelberg.

(72) Cho, C. H., Chuang, C. Y., Chen, C. F. (1986) Planta Med. 343.

(73) Schultes, R. E., Hofmann, A. (1980) Pflanzen der Götter. Hallwag, Bern, Stuttgart.

(74) Keeler, R. F. (1975) Lloydia 38, 56.

(75) Wink, M. (1984) Z. Naturforsch. 39c, 548.

(76) Wippich, C., Wink, M. (1985) Experientia 41, 1477.
(77) Wink, M. (1984) Z. Naturforsch. 39c, 553.

(78) Wink, M., Mende, P. (1987) Planta Med. 53, 465.

(79) Wink, M. (1983) Z. Naturforsch. 38c, 905.

(80) Harborne, J. B. (1982) Introduction to ecological biochemistry. Academic press, London, New York.

(81) Rosenthal, G. A., Janzen, D. H. (1979) Herbivores. Their interaction with secondary plant metabolites. Academic press, London, New York.

(82) Levin, D. A. (1976) Annu. Rev. Ecol. System. 7, 121.

(83) Swain, T. (1977) Annu. Rev. Plant Physiol. 28, 479.

(84) Boppre, M. (1986) Naturwissenschaften 73, 17.

(85) Wink, M., Hartmann, T. (1980) Planta Med. 40, 149.

(86) Wink, M. (1984) Naturwissenschaften 71, 635.

(87) Wink, M. (1985) J. Plant Physiol. 121, 287.

(88) Wink, M. (1987) In Cell culture in phytochemistry, vol. 4 (in press).

(89) Wink, M. (1987) In Plant vacuoles. Their importance in plant cell compartmentation and their applications in biotechnology (Marin, B., ed.) (in press).

(90) Wink, M. (1987) Plant cell, tissue and organ culture (in press).

(91) Schütte, H. R. (1982) Prog. Bot. 44, 166.

(92) Grundon, M. F. (1985) Nat. Prod. Rep. 2, 235.

(93) Herbert, R. B. (1986) Nat. Prod. Rep. 3, 185.

(94) Rana, J., Robins, D. J. (1985) J. Chem. Res. (S), 196.

(95) Rana, J., Robins, D. J. (1986) J. Chem. Soc. Perkin Trans. ${ }^{1} 1133$.

(96) Robins, D. J., Sheldrake, G. N. (submitted).

(97) Bell, E. A., Lackey, J. A., Polhill, R. M. (1978) Biochem. Syst. Ecol. 6, 201.

(98) Schneider, D. (1986) in: Perspectives in chemoreception and behavior (Chapman, R. F., Bernays, E. A., Stoffolano, J. G., eds.), pp. 123, Springer, New York.

(99) Spenser, I. D. (1985) Pure Appl. Chem. 57, 453.

(100) Golebiewski, W. M., Spenser, I. D. (1984) J. Am. Chem. Soc. 106,7925 . 